\title{
INDOOR AND OUTDOOR PM CONCENTRATIONS AT A RESIDENTIAL ENVIRONMENT, IN THE ATHENS AREA
}

\author{
E. DIAPOULI* \\ A. CHALOULAKOU \\ N. SPYRELLIS
}

Received: $23 / 04 / 08$

Accepted: 06/06/08

\author{
School of Chemical Engineering \\ National Technical University of Athens \\ 9, Heroon Polytechniou str., 15780 Zographos, Athens, Greece
}

*to whom all correspondence should be addressed: e-mail: diapouli@mail.ntua.gr

\section{ABSTRACT}

The aim of the present work was to study exposure to PM in the indoor and outdoor microenvironment of a typical residence in the center of Athens. Simultaneous indoor and outdoor measurements of $\mathrm{PM}_{10}$ and $\mathrm{PM}_{2.5}$ were conducted, by the use of gravimetric and continuous samples, during October and November 2006. Moreover, air exchange rate was monitored continuously during the entire measurement period.

The indoor and outdoor concentration levels were significant for both size fractions. Mean daily $\mathrm{PM}_{10}$ outdoor concentrations exceeded the E.U. 24-hr limit value for $84 \%$ of the measured days, while the respective $\mathrm{PM}_{2.5}$ concentrations exceeded the 24-hr limit value set by the C.A.F.E. working group for $69 \%$ of the measured days. $\mathrm{PM}_{10}$ and $\mathrm{PM}_{2.5}$ concentrations exhibited increased short-term variability with high peak concentrations during morning and afternoon/night rush hours.

Indoor concentration levels seem to be mainly affected by PM of outdoor origin, since the calculated indoor-to-outdoor concentrations ratios $(\mathrm{I} / \mathrm{O})$ were much lower than 1.00 during all days and indoor and outdoor concentrations were highly correlated. This finding was also supported by the pattern of their diurnal cycles, which followed the outdoor ones, with a delay of approximately $1 \mathrm{hr}$.

The results indicate increased PM concentration levels in the center of Athens, even in indoor microenvironments with no significant indoor sources and emphasize the need for a more extensive investigation of the Athens population exposure, for the protection of public health.

KEYWORDS: $\mathrm{PM}_{10} / \mathrm{PM}_{2.5}$, indoor - outdoor, residential microenvironment.

\section{INTRODUCTION}

Epidemiological and experimental evidences have associated exposure to particulate matter (PM) with excesses in daily mortality and morbidity (Pope and Dockery, 2006; Katsouyanni et al., 2001). Lately, special attention has been given to indoor air quality, since, in big urban centers, people spend more than $85 \%$ of their time in indoor microenvironments. According to relevant studies, $62-87 \%$ of the day is spent in the residential microenvironment, which may be therefore critical for the daily total personal exposure of the population (Adgate et al., 2002; Klepeis et al., 1996).

Indoor concentration levels may be attributed to indoor and outdoor sources. Indoor sources include particle generation (related to combustion processes, use of spray products) and particle resuspension during intense movement and activity (Nazaroff, 2004; Wallace, 1996). Nevertheless, except for the different indoor sources, particles of outdoor origin also contribute significantly to the indoor concentration levels (Riley et al., 2002; Ozkaynak et al., 1996). A critical parameter influencing the penetration of outdoor particles into the indoor microenvironment is air exchange rate $(\alpha)$.

The city of Athens has been facing air pollution episodes during the last three decades (Chaloulakou et al., 2003a). Central residential areas are greatly affected by the intense traffic density in the nearby commercial areas, which leads to very high ambient PM concentration 
levels in the Athens center. The aim of the present work was to study exposure to $\mathrm{PM}_{10}$ and $\mathrm{PM}_{2.5}$ in the indoor and outdoor microenvironment of a typical residence in the center of Athens. Indoor and outdoor PM levels were examined (both in a daily and short-term basis) and their relationships were studied. The values of indoor-to-outdoor concentration ratio were also considered, in relation to the air exchange rate of the under study residence.

\section{METHODS}

Measurements were conducted in a typical residence in the center of Athens, during October and November 2006. The area selected is strictly residential but densely populated and in close proximity to a major avenue and commercial areas. The residence is located at the first floor of an apartment building and is inhabited by a non-smoking person. No ventilation system exists (as in most residences in the center of Athens) and windows remained closed during the measurement campaign. Indoor samplers were placed in the living room, at breathing height. Outdoor measurements were conducted on the terrace, just outside the under study room.

Simultaneous indoor and outdoor $\mathrm{PM}_{10}$ and $\mathrm{PM}_{2.5}$ measurements were conducted in alternative days, by the use of Harvard PEMs (ChemPass Personal Sampling System, Model 3400, R\&P Air Quality Instrumentation) at a flow rate of $4 \mathrm{I} \mathrm{min}^{-1}$.

Additionally, DustTrak monitors (Model 8520, TSI Inc.) were used for the continuous monitoring of indoor and outdoor $\mathrm{PM}_{10}$ and $\mathrm{PM}_{2.5}$ concentrations. The instruments were programmed to record every $1 \mathrm{~min}$.

DustTrak monitors were factory-calibrated for the respirable fraction of standard ISO 12103-1, A1 test dust (Arizona Test Dust), which is representative for a wide variety of aerosols and has a resolution of $0.001 \mathrm{mg} \mathrm{m}^{-3}$. It has been shown that DustTrak does not provide really precise measurements but presents very high correlations when compared to gravimetric samplers (Diapouli, 2008; Kim et al., 2004). In the present work, a correction procedure used by Ramachandran et al. (2000) was followed for all data obtained by DustTrak, indoors and outdoors: A correction factor (CF) was computed for each measurement day. CF was calculated as the ratio of the gravimetric indoor or outdoor concentration obtained by Harvard PEMs, over a measurement period $(T)$, to the respective time integrated DustTrak respective concentration over the same time period $(T)$. All concentration values obtained by DustTrak were then corrected (multiplied) by this CF.

During the entire PM measurement period, air exchange rate was also continuously monitored with the use of $\mathrm{SF}_{6}$ as tracer gas. The "constant concentration" method was applied by the use of multipoint sampler and doser (model 1303) and photoacoustic multi-gas monitor (model 1312), Innova AirTech Instruments.

Meteorological data for the measurement period were obtained from the Meteorological Station of the National Technical University of Athens.

\section{RESULTS}

Measurements were conducted during October and November 2006. The meteorological conditions during the measurement period are summarized in Table 1.

The mean daily concentrations of $\mathrm{PM}_{10}$ and $\mathrm{PM}_{2.5}$ measured indoors and outdoors are presented in Figures 1 and 2 respectively. The 24-hr limit value set by the E.U. for the ambient concentration of $\mathrm{PM}_{10}$ is also shown in Figure 1. Since there is presently no 24-hr limit value for $\mathrm{PM}_{2.5}$, for comparison reason, the proposed by the C.A.F.E. working group limit value of $35 \mu \mathrm{g} \mathrm{m}^{-3}$ is used (C.A.F.E. Working Group, 2004). Outdoor concentrations exceeded the above limit values $84 \%$ of the measured days for $\mathrm{PM}_{10}$ and $69 \%$ for $\mathrm{PM}_{2.5}$. Outdoor concentrations presented a high day-to-day variability for both size fractions. The arithmetic mean of daily concentrations during weekends was lower than the corresponding weekdays one, especially for $\mathrm{PM}_{10}\left(\mathrm{PM}_{10}\right.$ : Mean-weekends $=68.2 \mu \mathrm{g} \mathrm{m}{ }^{-3}$ and Mean-weekdays $=96.3 \mu \mathrm{g} \mathrm{m}^{-3}$, $\mathrm{PM}_{2.5}$ : Mean-weekends $=48.0 \mu \mathrm{g} \mathrm{m}^{-3}$ and Mean-weekdays $=52.4 \mu \mathrm{g} \mathrm{m}^{-3}$ ), possibly due to the increased traffic density during working days. 
Table 1. Descriptive statistics of the daily values of meteorological parameters during the measurement period: Temperature ( $T$ ), Relative Humidity $(\mathrm{RH})$, Wind Speed $(\mathrm{Ws})$.

\begin{tabular}{lcccc}
\hline & Mean & Median & Minimum & Maximum \\
\hline T ( $\left.{ }^{\circ} \mathbf{C}\right)$ & 15.5 & 15.3 & 5.2 & 22.2 \\
RH (\%) & 70.4 & 69.3 & 41.4 & 86.2 \\
Ws $\left(\mathbf{m ~ m i n}^{-1}\right.$ ) & 1.9 & 1.2 & 0.3 & 5.8 \\
\hline
\end{tabular}

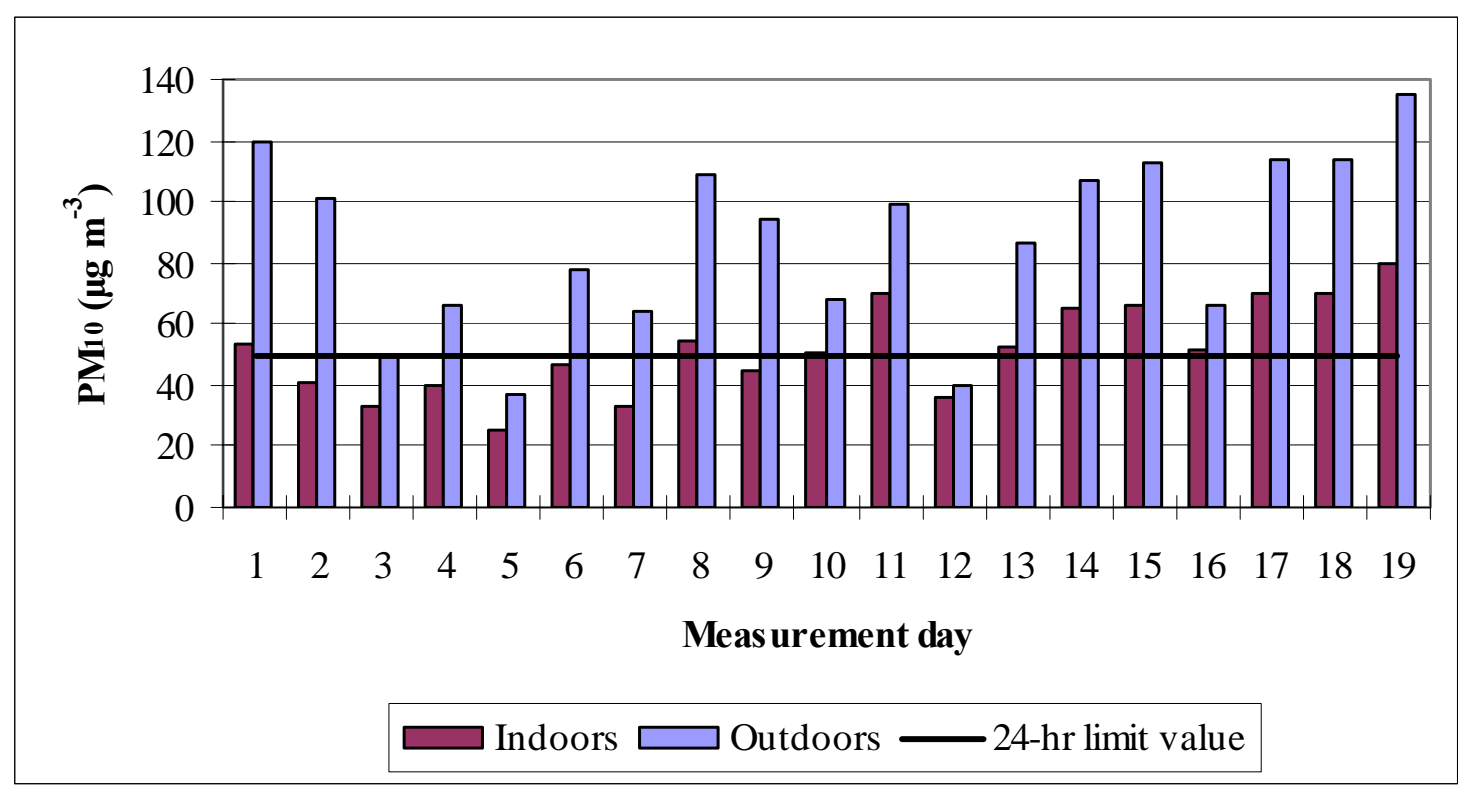

Figure 1. $\mathrm{PM}_{10}$ mean daily concentration levels

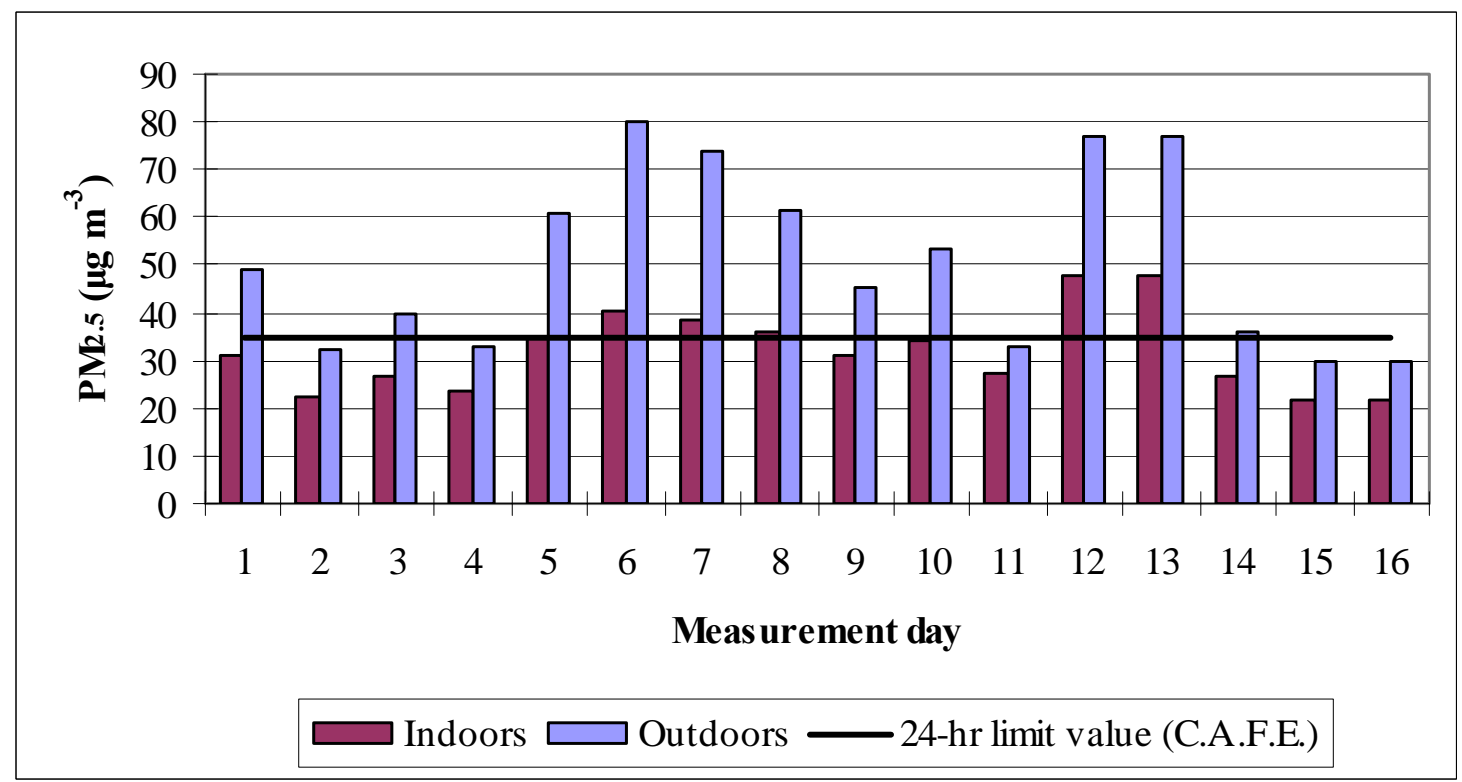

Figure 2. $\mathrm{PM}_{2.5}$ mean daily concentration levels

Nevertheless, outdoor concentration levels seem to be more affected by the prevailing wind conditions. Specifically, a negative correlation was observed between daily mean PM concentrations and daily mean or hourly maximum values of wind speed (Figures 3 and 4) (Chaloulakou et al., 2005; Chaloulakou et al., 2003a). 


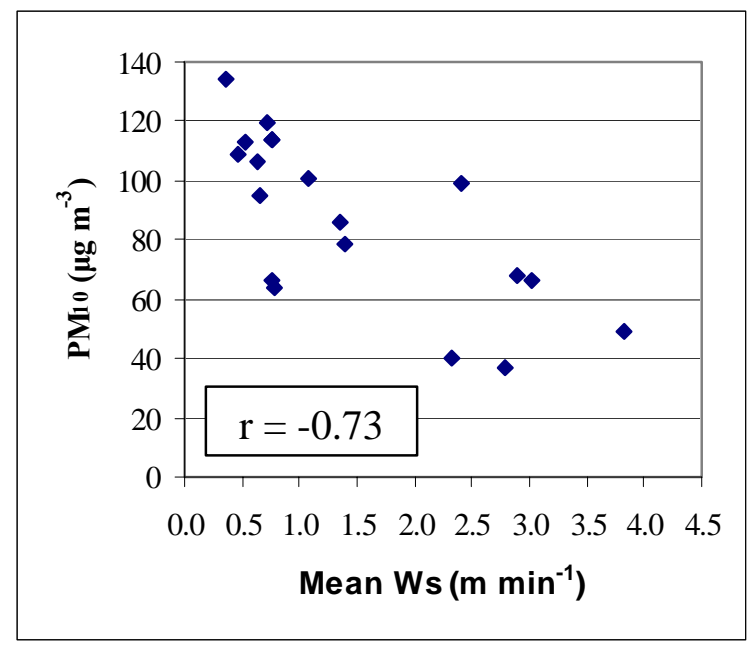

(a)

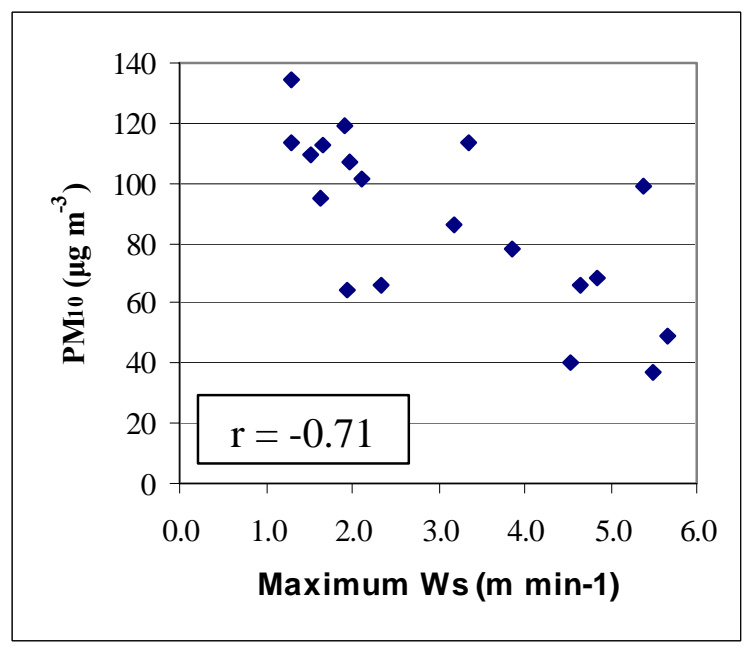

(b)

Figure 3. Correlation between mean daily values of $\mathrm{PM}_{10}$ concentrations and: a) mean daily values of wind speed and $b$ ) hourly maximum daily values of wind speed

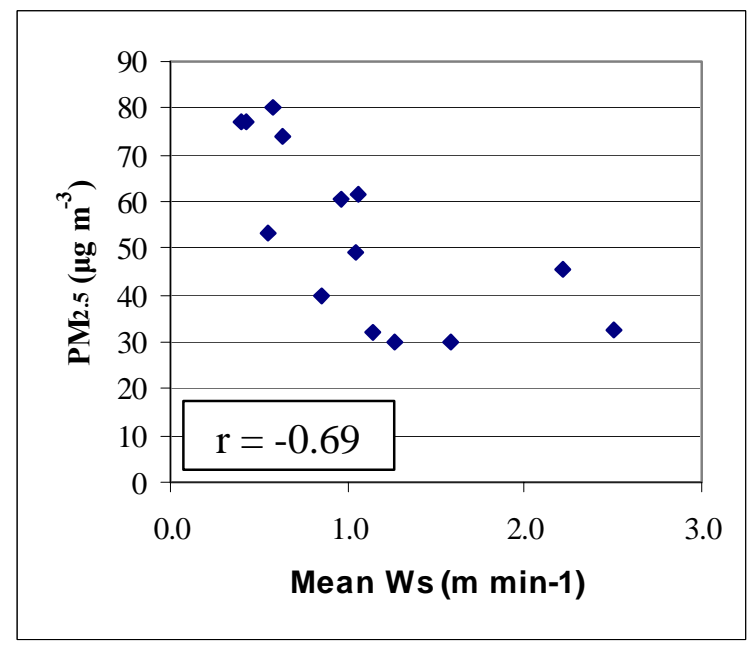

(a)

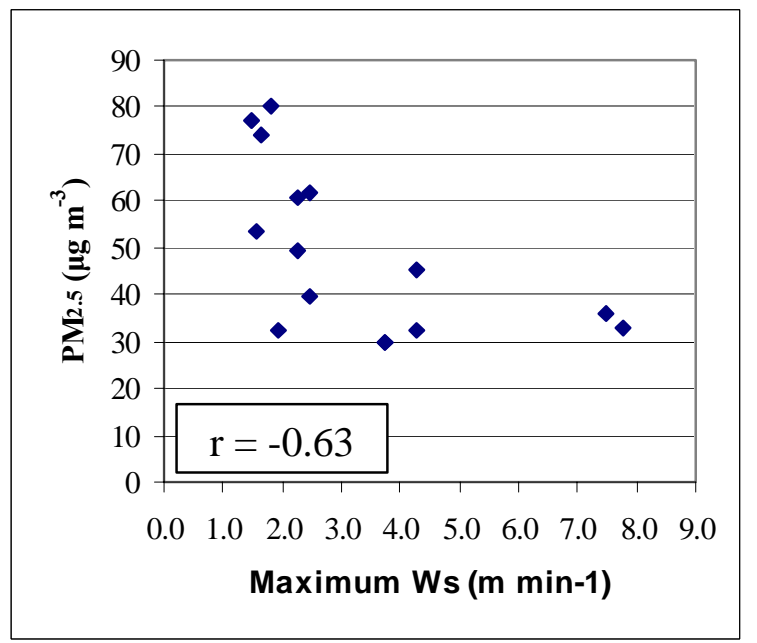

(b)

Figure 4. Correlation between mean daily values of $\mathrm{PM}_{2.5}$ concentrations and: a) mean daily values of wind speed and $b$ ) hourly maximum daily values of wind speed

Indoor concentrations were consistently lower than the outdoor ones but not insignificant. Mean daily indoor concentrations exceeded the 24-hr ambient limit values $58 \%$ of the days for $\mathrm{PM}_{10}$ and $30 \%$ of the days for $\mathrm{PM}_{2.5}$. Indoor concentration levels presented smoother dayto-day variation than the corresponding outdoor, which may be attributed to the similarity of activities during the measurement period and the weaker influence of meteorological conditions to the indoor particle levels.

The ratio of indoor-to-outdoor concentrations $(\mathrm{I} / \mathrm{O})$ may give an insight on the relative contribution of indoor and outdoor sources to the indoor concentration levels. The calculated $\mathrm{I} / \mathrm{O}$ ratios at the under study residence were equal to $0.61 \pm 0.12$ for $\mathrm{PM}_{10}$ and $0.66 \pm 0.09$ for $\mathrm{PM}_{2.5}$. These values, much lower than 1.00 , indicate the absence of significant indoor sources and, therefore, the great contribution of outdoor particles to the indoor concentration levels. This finding is also supported by the strong correlation between mean daily indoor and outdoor concentrations, for both $\mathrm{PM}_{10}$ and $\mathrm{PM}_{2.5}$ (Figures 5 and 6 ). The higher values of the $\mathrm{PM}_{2.5} \mathrm{I} / \mathrm{O}$ ratio in comparison to the corresponding $\mathrm{PM}_{10}$ ones are related to the increased infiltration of fine outdoor particles due to their smaller size. 


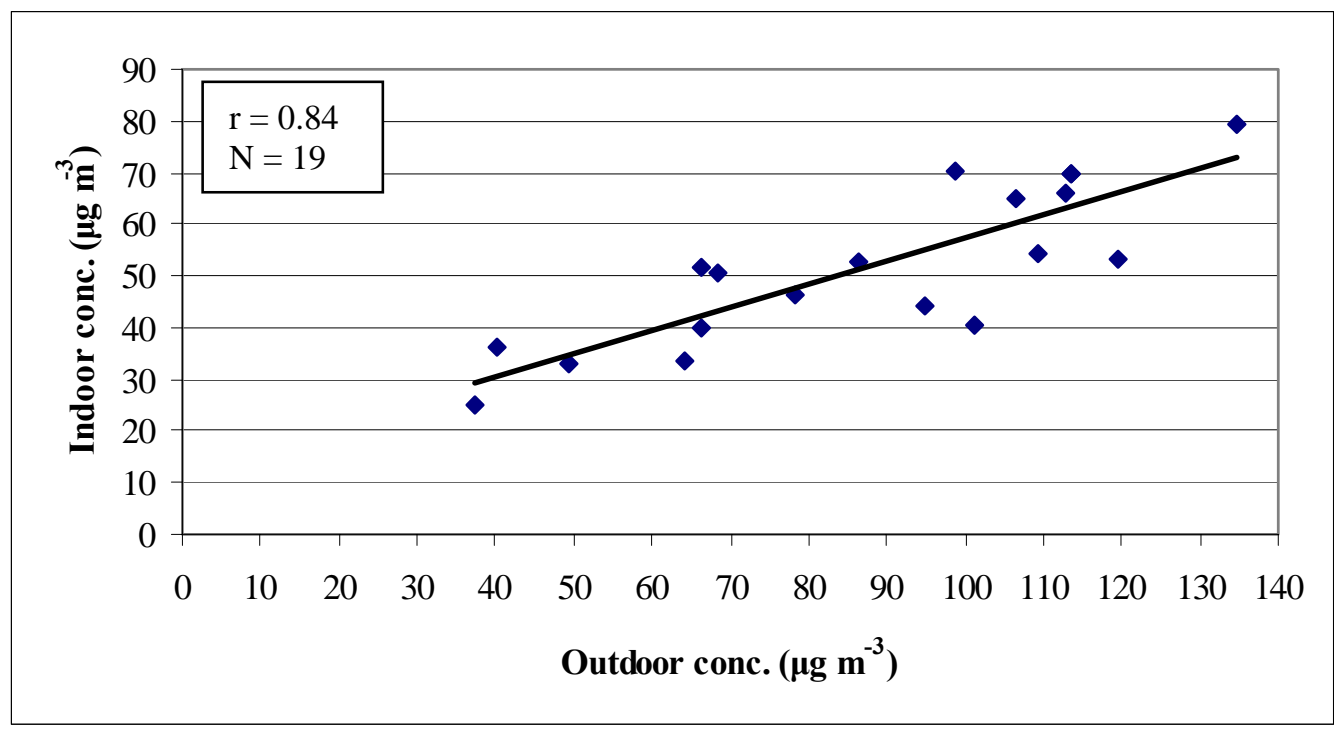

Figure 5. Correlation between indoor and outdoor daily $\mathrm{PM}_{10}$ concentrations

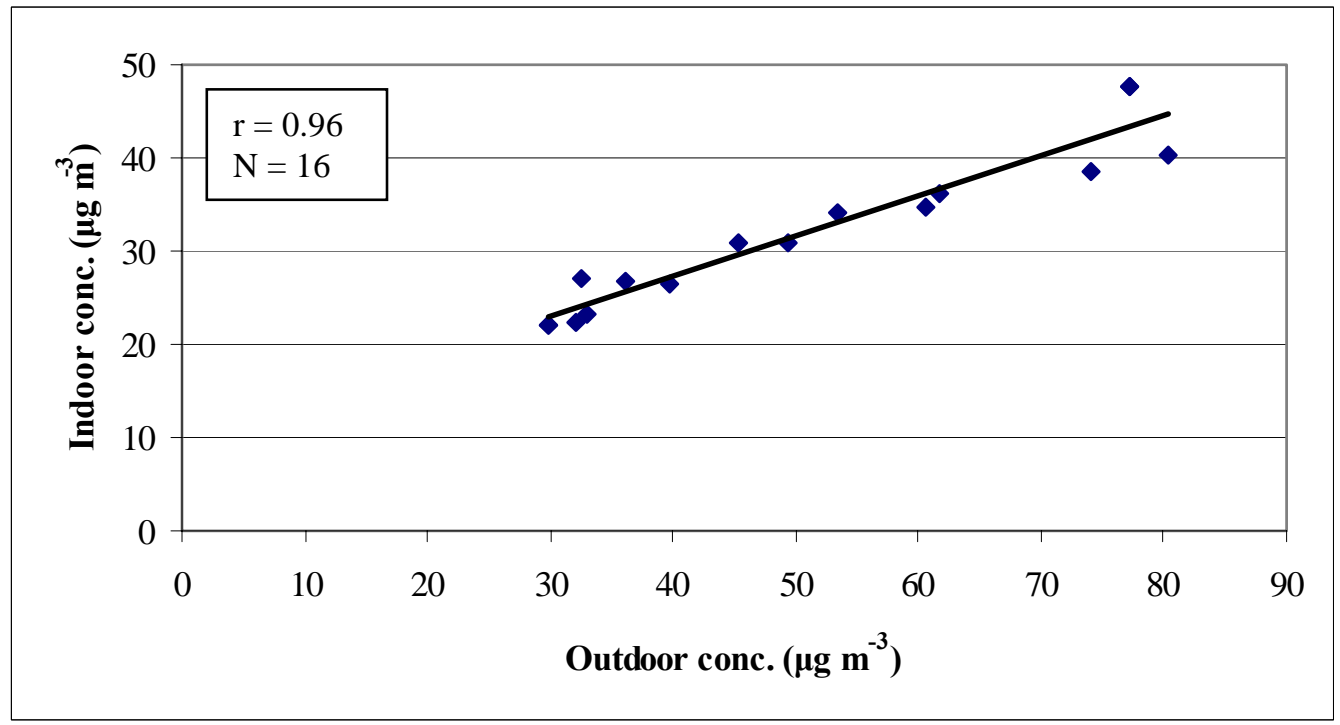

Figure 6. Correlation between indoor and outdoor daily $\mathrm{PM}_{2.5}$ concentrations

The measured air exchange rates were moderate, since windows remained closed throughout the experimental campaign. The daily values of indoor-to-outdoor concentrations ratios were positively correlated with the corresponding values of air exchange rate $(\alpha)$ (Figures $7 a$ and b). Higher air exchange rates facilitated the infiltration of outdoor particles in the residence, resulting in increased indoor concentrations and thus higher $1 / O$ ratios. This effect seems more pronounced in $\mathrm{PM}_{10}$, which, due to their larger size, have smaller penetration efficiency than fine particles and depend more on air exchange rate for their transport in the indoor microenvironment (Diapouli, 2008).

The use of continuous monitors allowed for the study of diurnal cycles of indoor and outdoor concentrations. Outdoor concentrations of both PM fractions followed in general the same pattern, with two distinct peaks, during morning and afternoon/night rush hours. Mean diurnal cycles of outdoor $\mathrm{PM}_{10}$ concentrations during weekdays and weekends are presented in Figure 8. The morning peak that appears only on weekdays clearly reflects the intense morning traffic during working days. The nighttime peaks were higher and of longer duration and appeared on weekends as well. They may de attributed partly to traffic and central heating but may be also related to differences in meteorological conditions during morning and nighttime. 


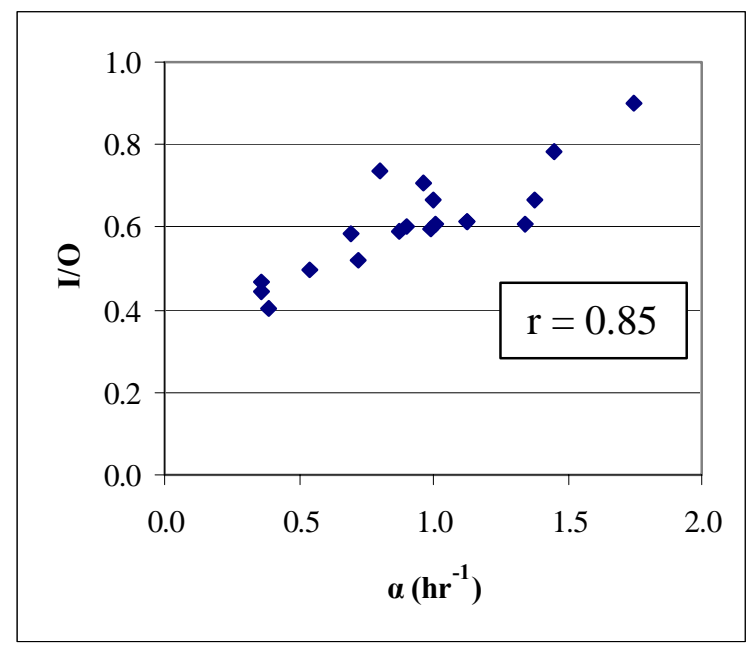

(a)

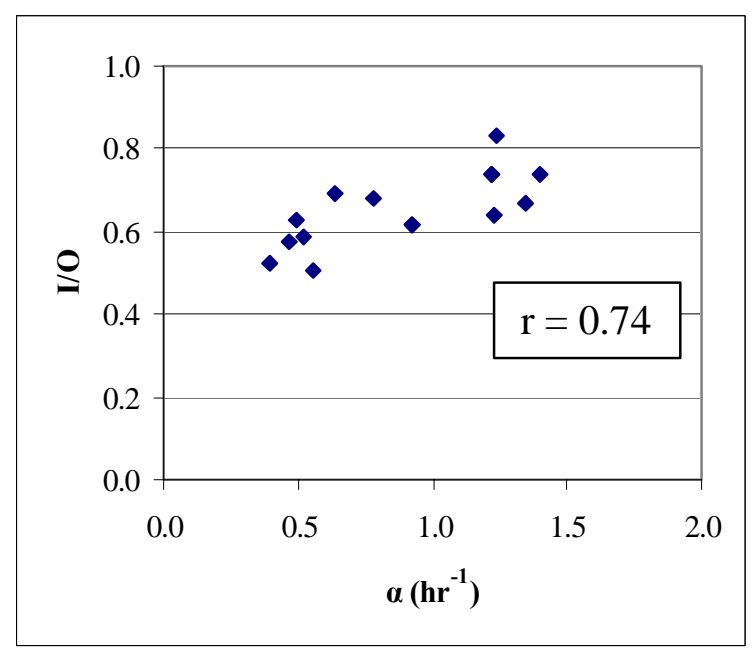

(b)

Figure 7. Correlation between mean daily values of $\mathrm{I} / \mathrm{O}$ ratios and air exchange rates for: a) $\mathrm{PM}_{10}$ and b) $\mathrm{PM}_{2.5}$

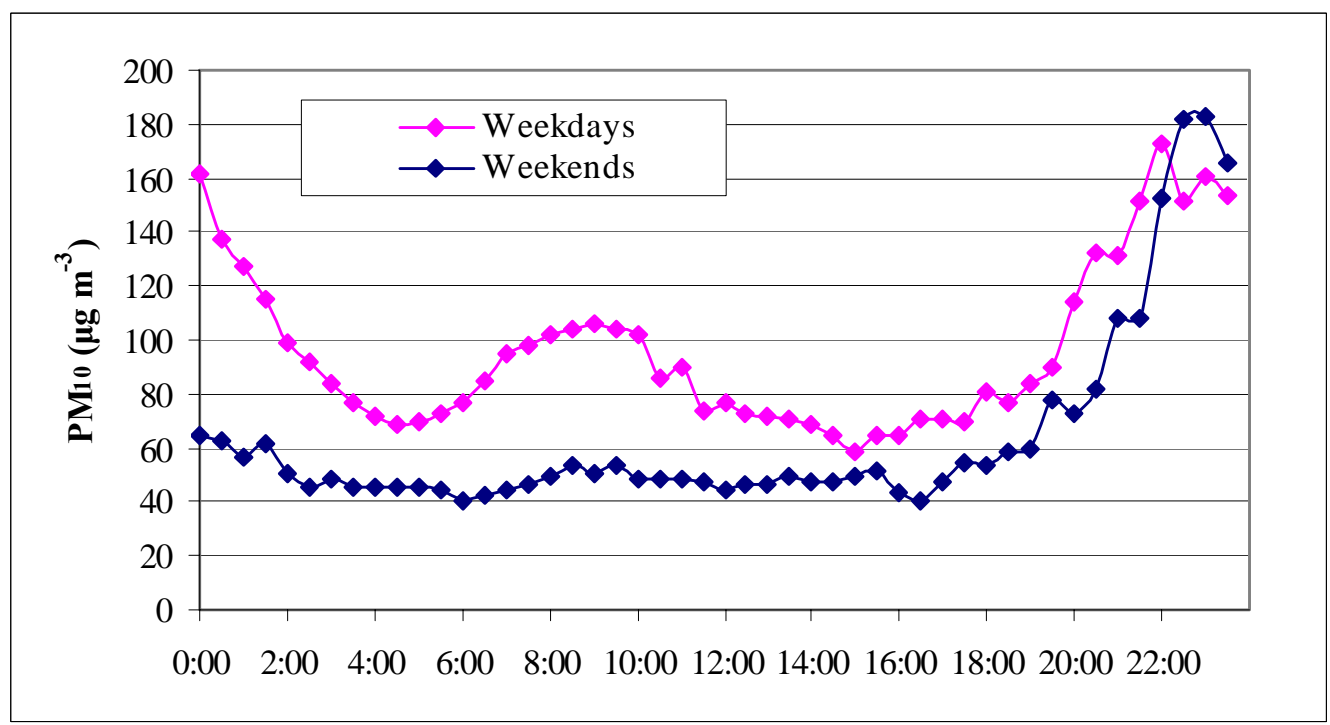

Figure 8. Mean diurnal cycles of $\mathrm{PM}_{10}$ outdoor concentrations, during weekdays and weekends

In what concerns indoor concentrations, their diurnal cycles were examined in relation to the respective outdoor ones, in order to identify the contribution of indoor or outdoor sources in the observed short-term variation of concentrations. During all days, $\mathrm{PM}_{10}$ and $\mathrm{PM}_{2.5}$ indoor concentrations followed the outdoor ones, indicating that no significant indoor particle generation occurred. According to the resident's time-activity diary, the under study room was empty during most of the day. His presence during 1 or 2 hours daily did not affect the indoor concentration levels, since there were no incidents of intense activity or smoking, which are generally known to lead to increased PM concentrations (Diapouli et al., 2007; Hussein et al., 2006). In Figure 9, $\mathrm{PM}_{2.5}$ indoor and outdoor concentration diurnal cycles on a specific day are presented indicatively. Their patterns are characteristic of both $\mathrm{PM}_{10}$ and $\mathrm{PM}_{2.5}$ concentrations. Specifically, indoor concentrations followed the outdoor ones with a delay of $30 \mathrm{~min}$ to $1.5 \mathrm{hr}$. This behavior has been observed by a number of researchers, for PM and gaseous pollutants (Hussein et al., 2005; Chaloulakou et al., 2003b; Morawska et al., 2001). Moreover, the diurnal cycles of indoor concentrations presented a lower short-term variation, indicating a "smoothing" of the intense outdoor concentration variations in the indoor microenvironments (Koponen et al., 2001; Freijer \& Bloemen, 2000). 


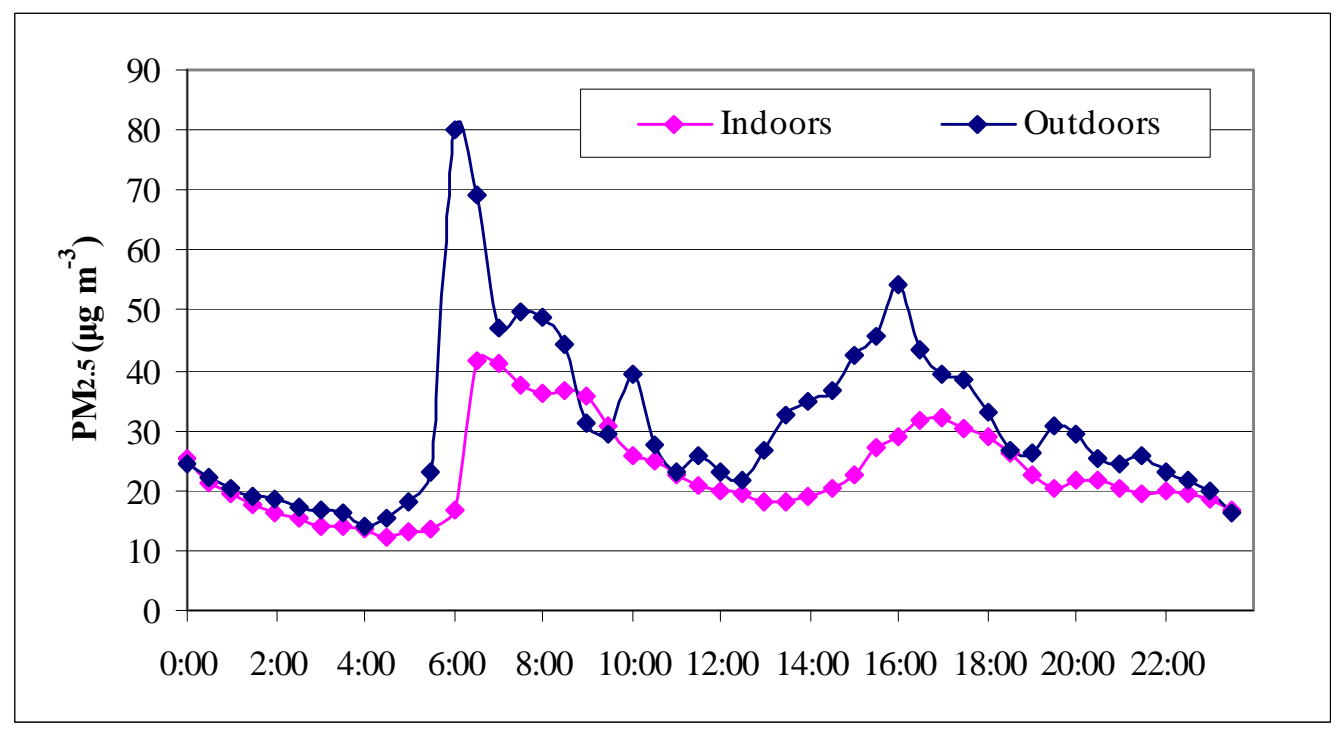

Figure 9. Diurnal cycles of $\mathrm{PM}_{2.5}$ indoor and outdoor concentrations on Monday, 13/11/2006.

\section{CONCLUDING REMARKS}

The aim of the present work was to study exposure to PM in a critical -for the personal population exposure- microenvironment, such as the residential microenvironment. A typical residence in the center of Athens was selected and indoor and outdoor $\mathrm{PM}_{10}$ and $\mathrm{PM}_{2.5}$ concentrations, as well as their relationships, were examined.

The measured outdoor concentration levels were significant for both size fractions. Mean daily $\mathrm{PM}_{10}$ outdoor concentrations exceeded the E.U. 24-hr limit value for 16 out of 19 days measured, while according to E.U. legislation the 24-hr limit value may be exceeded only for 35 days in a yearly basis. Outdoor concentrations exhibited a high day-to-day and short-term variation. The obtained diurnal cycles revealed very high peak concentrations during morning and afternoon/night rush hours.

Indoor $\mathrm{PM}_{10}$ and $\mathrm{PM}_{2.5}$ concentrations were consistently lower than the outdoor ones but not insignificant. Indoor concentration levels seem to be mainly affected by PM of outdoor origin, since the calculated indoor-to-outdoor concentrations ratios $(\mathrm{I} / \mathrm{O})$ were much lower than 1.00 during all days and indoor and outdoor concentrations were highly correlated. This finding was also supported by the pattern of their diurnal cycles, which followed the outdoor ones, with a delay of approximately $1 \mathrm{hr}$.

The results indicate increased PM concentration levels in the center of Athens, even in indoor microenvironments with no significant indoor sources. Outdoor particles enter these microenvironments, even with closed windows and at moderate air exchange rates, as the ones measured $\left(0.5-1.5 \mathrm{hr}^{-1}\right)$, leading to high indoor concentrations, especially during rush hours, when outdoor concentration are extremely elevated.

A more extensive investigation, including other types of indoor sites where indoor sources are also expected to be present (such as the work microenvironment), would contribute greatly to the assessment of the Athens population exposure to PM, and to the implementation of corrective actions for the protection of public health.

\section{REFERENCES}

1. Adgate J.L., Ramachandran G., Pratt G.C., Waller L.A., Sexton K. (2002), Spatial and temporal variability in outdoor, indoor, and personal $\mathrm{PM}_{2.5}$ exposure, Atmospheric Environment, 36, 3255-3265.

2. C.A.F.E. Working Group in Particulate Matter (2004), Second position paper on particulate matter. 
3. Chaloulakou A., Kassomenos P., Grivas G., Spyrellis N. (2005), Particulate matter and black smoke concentration levels in central Athens, Greece, Environment International, 31, 651-659.

4. Chaloulakou A., Kassomenos P., Spyrellis N., Demokritou P., Koutrakis P. (2003a), Measurements of $\mathrm{PM}_{10}$ and $\mathrm{PM}_{2.5}$ particle concentrations in Athens, Greece, Atmospheric Environment, 37, 649-660.

5. Chaloulakou A., Mavroidis I., Duci A. (2003b), Indoor and outdoor carbon monoxide concentration relationships at different microenvironments in the Athens area, Chemosphere, 52, 1007-1019.

6. Diapouli E. (2008), Exposure to PM of different population subgroups - Contribution of indoor and outdoor sources, PhD Thesis.

7. Diapouli E., Chaloulakou A., Spyrellis N. (2007), Indoor and outdoor particulate matter concentrations at schools in the Athens area, Indoor and Built Environment, 16, 55-61.

8. Freijer J.I., Bloemen J.Th. (2000), Modeling relationships between indoor and outdoor air quality, Journal of the Air and Waste Management Association, 50, 292-300.

9. Hussein T., Glytsos T., Ondracek J., Dohanyosova P., Zdimal V., Hameri K., Lazaridis M., Smolik J., Kulmala M. (2006), Particle size characterization and emission rates during indoor activities in a house, Atmospheric Environment, 40, 4285-4307.

10. Hussein T., Hameri K., Heikkinen M.S.A., Kulmala M. (2005), Indoor and outdoor particle size characterization at a family house in Espoo - Finland, Atmospheric Environment, 39, 36973709.

11. Katsouyanni K., Touloumi G., Samoli E., Gryparis A., La Tertre A., Monopolis Y., Rossi G., Zmirou D., Ballester F., Boumghar A., Anderson H.R., Wojtyniak B., Paldy A., Braunstein R., Pekkanen J., Schindler C., Schwartz J. (2001), Confounding and effect modification in the short-term effects of ambient particles on total mortality: Results from 29 European cities within the APHEA2 project, Epidemiology, 12, 521-531.

12. Kim Y.J., Magari S.R., Herrick R.F., Smith T.J., Christiani D.C. (2004), Comparison of fine particle measurements from a direct-reading instrument and a gravimetric sampling method, Journal of Occupational and Environmental Hygiene, 1, 707-715.

13. Klepeis N.P., Tsang A.M., Bejar J.V. (1996), Analysis of the national human activity pattern survey respondents from a standpoint of exposure assessment, U.S. Environmental Protection Agency, Las Vegas, NV.

14. Koponen I.K., Asmi A., Keronen P., Puhto K., Kulmala M. (2001), Indoor air measurement campaign in Helsinki, Finland 1999 - The effect of outdoor air pollution on indoor air, Atmospheric Environment, 35, 1465-1477.

15. Morawska L., He C., Hitchins J., Gilbert D., Parappukkaran S. (2001), The relationship between indoor and outdoor airborne particles in the residential environment, Atmospheric Environment, 35, 3463-3473.

16. Nazaroff W.W. (2004), Indoor particle dynamics, Indoor Air, 14(Suppl.7), 175-183.

17. Ozkaynak H., Xue J., Spengler J., Wallace L., Pellizzari E., Jenkins P. (1996), Personal exposure to airborne particles and metals. Results from the Particle TEAM study in Riverside, California, Journal of Exposure Analysis and Environmental Epidemiology, 6, 57-78.

18. Pope C.A., Dockery D.W. (2006), Health effects of fine particulate air pollution: Lines that connect, Journal of the Air and Waste Management Association, 56, 709-742.

19. Ramachandran G., Adgate J.L., Hill N., Sexton K., Pratt G.C., Bock D. (2000), Comparison of short-term variations (15-min averages) in outdoor and indoor $\mathrm{PM}_{2.5}$ concentrations, Journal of Air and Waste Management Association, 50,1157-1166.

20. Riley W.J., McKone T.E., Lai A.C., Nazaroff W.W. (2002), Indoor particulate matter of outdoor origin: Importance of size-dependent removal mechanisms, Environmental Science and Technology, 37, 200-207.

21. Wallace L. (1996), Indoor particles: A review, Journal of the Air and Waste Management Association, 46, 98-126. 